\title{
Avaliação comparativa dos índices de lesão, dor e da qualidade de vida em lesados medulares sedentários e praticantes de basquetebol em cadeira de rodas
}

Considerando-se os interesses científicos e assistenciais vinculados à promoção da qualidade de vida de portadores de lesão medular, eu li com muito interesse o artigo escrito por Leandro Stetner Antonietti, Renata Alqualo Costa, Francine Lopes Barreto Gondo, Acary Souza Bulle Oliveira e Berenice Chiarello da Universidade Federal de São Paulo, entitulado: “Avaliação comparativa dos índices de lesão, dor e da qualidade de vida em lesados medulares sedentários e praticantes de basquetebol em cadeira de rodas".

O estudo teve como objetivo avaliar a incidência de lesões e dor como também analisar, avaliar e comparar os escores indicativos de uma melhora na qualidade de vida em indivíduos lesados medulares. Participaram do estudo quinze indivíduos da modalidade de basquetebol em cadeira de rodas comparando com doze indivíduos sedentários com lesão medular. Para avaliação dos aspectos relacionados à Dor e lesão músculo esquelética foi utilizado o IMR e para a avaliação da qualidade de vida o WHOQOL-bref.

Do ponto de vista histórico, o interesse pela lesão medular não é recente. Papiros egípcios, escritos há 5000 anos, já revelavam o desafio terapêutico imposto por esses casos 1. Vale lembrar que até a década de 1940, aqueles que adquiriam uma lesão faleciam pouco tempo depois. Os que resistiam dificilmente reconquistavam sua integração psicossocial ao longo dos dois a três anos de sobrevida estimados naquela época. À medida que recursos terapêuticos foram aprimorados e se tornaram mais acessíveis, a média de sobrevivência aumentou. Com isso, veteranos da Segunda Guerra Mundial incapacitados, mutilados e necessitando de atenção integral, passaram a lotar abrigos e hospitais.

A lesão medular é um evento traumático gerador de grande imprevisibilidade, pois mudanças físicas irreversíveis bloqueiam a capacidade da pessoa em realizar suas necessidades primordiais. O traumatismo raquimedular é uma agressão à medula espinhal, que pode resultar em perda de movimentos voluntários e/ou sensibilidade (tátil, dolorosa, profunda) ao nível dos membros superiores e/ou inferiores e em alterações no funcionamento dos sistemas urinário, intestinal, respiratório, circulatório, sexual e reprodutivo2,3. As lesões traumáticas compõem $80 \%$ do total das lesões medulares, sendo causadas, geralmente, por acidentes de trânsito, projétil de arma de fogo, armas brancas, quedas e acidentes de trabalho ou de prática de esporte. Quanto às lesões não-traumáticas (20\%), as causas mais freqüentes são: tumorais, infecciosas, vasculares, degenerativas e malformações4. De acordo com as estimativas disponíveis para a população mundial, cerca de 20 a 40 indivíduos por milhão, são portadores de lesão medular, sendo que o segmento proporcionalmente mais atingido é constituído por jovens do sexo masculino e com menos anos de escolaridade formal5.

Visando a importância do esporte em lesados medulares De Mello et al6, avaliaram o padrão e as queixas de sono em indivíduos portadores de deficiência por secção total da medula através da aplicação de um questionário. Foram avaliados 59 portadores de secção medular divididos em desportistas e não desportistas e os resultados da pesquisa constataram que a categoria de desportistas teve uma maior variabilidade de média de horas dormidas ao longo da semana. Foram encontradas diferenças significativas entre desportistas e não desportistas na incidência de ronco (20\% e 47\%), despertares noturnos (64\% e 35\%) e movimentos de membros inferiores $(72 \%$ e $38 \%$ ). Estes resultados podem ser explicados por uma maior excitabilidade dos circuitos intrínsecos da medula, gerando tônus muscular e automatismos maiores na categoria de desportistas.

A pesquisa publicada neste número "Avaliação comparativa dos índices de lesão, dor e da qualidade de vida em lesados medulares sedentários e praticantes de basquetebol em cadeira de rodas", apresentou resultados interessantes que a apontam na articulação do ombro uma maior prevalência de dor e lesões, em ambos os grupos. Os desportistas apresentaram maiores escores nos aspectos físico, psicológico e de relações pessoais no WHOQOL-bref. No entanto aspectos importantes a se ressaltar é que grande parte dos lesados medulares, como já praticavam esportes antes da lesão medular, mantiveram a pratica de esportes após a lesão. Outro aspecto importante é que o fator tempo de reabilitação parece ser diferente para a motivação e iniciação ao esporte paraolímpico.

Com relação às lesões músculo-esqueléticas, foi observado que $66,67 \%$ dos sedentários apresentaram alguma lesão nos últimos doze meses, e que $86,67 \%$ dos desportistas também apresentaram lesões neste mesmo período. Esses resultados corroboram com o estudo de Pate et al7 em que a porcentagem de desportistas com algum tipo de lesão por trauma direto ou uso excessivo em eventos competitivos em curso foi de $60,6 \%$.

Com os resultados do presente estudo é possível afirmar que não houve diferença estatisticamente significante entre os grupos no que diz respeito ao número de indivíduos que apresentavam alguma lesão. E concordo com a hipótese de que os lesados medulares sedentários apresentam a mesma proporção de lesões que os desportistas com a mesma condição de base. Isso pode ser pelo fato de que os lesados medulares sedentários também necessitam de adaptações para executar suas AVDs e acabam por sobrecarregar seus membros não acometidos, no caso dos paraplégicos, os membros superiores. Porém, os desportistas avaliados nesta amostragem não são de alto rendimento, apresentando, portanto, atividades bastante semelhantes as dos indivíduos sedentários.

Os autores do presente estudo concluem que os LM desportistas apresentam lesões como os sedentários, porém, com qualidade de vida melhor, sugerindo que o esporte adaptado é uma importante via para a reabilitação destes indivíduos.

No meu ponto de vista, ambos os grupos necessitam do esporte para melhorar os aspectos social, pessoal e físico, pois os desportistas apresentam uma melhora na qualidade de vida em relação aos sedentários. 
No entanto é importante observar qual a porcentagem dos desportistas que nunca praticaram outra modalidade esportiva. Este fato pode estar relacionado à falta de oportunidade ou motivação para novas experiências esportivas, o que deve ser minimizado com a oferta e motivação desses indivíduos a outros esportes.

Não acredito que somente o estimulo à pratica esportiva seja o fator primordial para a inclusão de lesados medulares sedentários ao esporte paraolímpico. O habito ou não da pratica esportiva está presente em qualquer tipo de população e deve ser respeitado, mas deve ser sempre esclarecidos os benefícios da pratica para que o indivíduo esteja sempre consciente de suas ações e atividades .

Assim, o presente estudo é importante e trará grande contribuição à comunidade científica da área especifica do estudo.

\section{REFERÊNCIAS BIBLIOGRÁFICAS}

1. Yarkony GM. Spinal cord injury-medical management and rehabilitation. Gaithersburg. Maryland: Aspen, 1994, 236p.

2. Staas Jr. WE, Formal CS, Gershkoff AM, Freda M, Hirschwald JF, Miller GT, et al. Reabilitação do paciente com traumatismo raquimedular. In: DeLisa JA (Ed.). Medicina de reabilitação. Princípios e prática. São Paulo: Manole, 1992, 735-63.

3. Stiens SA, Bergman SB, Formal CS. Spinal cord injury rehabilitation. 4. Individual experience, personal adaptation and social perspectives. Arc Phys Med Rehab 1997;78:65-72.

4. Lianza S, Casalis ME, Greve JMD, Eichberg R. A lesão medular. In: Lianza S (Ed.). Medicina de reabilitação Rio de Janeiro: Guanabara Koogan, 2001, 299-322.

5. Meyers AR. The epidemiology of traumatic spinal cord injury in the United States. In: Nesathurai S (Ed.). The rehabilitation of people with spinal cord injury. Boston: Boston Medical Center, 2001, 9-13.

6. De Mello MT, Lauro FAA, Silva AC, Tufik S. Sleep study after acute physical activity in spinal cord injury. Sleep Res 1995;24A(Abs suppl):391.

7. Pate RR, Pratt M, Blair SN, Haskell WL, Macera CA, Bouchard

C, et al. Physical activity and public health: a recommendation from the Centers for Disease Control and Prevention and the American College of Sports Medicine. JAMA 1995;273:402-7.
Marco Túlio de Mello

Livre Docente do Departamento de Psicobiologia Chefe da Disciplina Biologia e Medicina do Sono Universidade Federal de São Paulo - UNIFESP Coordenador do CEPE/CEMSA Pesquisador CNPq 